\title{
EDUCAÇÃO SUPERIOR E ESCOLHA PROFISSIONAL NO BRASIL
}

\author{
Caio Rudá*

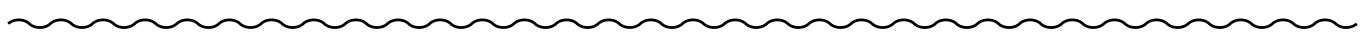 \\ Autor correspondente: Caio Rudá - caioruda.o@gmail.com \\ *Psicólogo e mestre em Estudos Interdisciplinares sobre a Universidade, pela Universidade Federal da Bahia. Vice- \\ coordenador do Núcleo Bahia da Associação Brasileira de Ensino de Psicologia
}

Resumo

\begin{abstract}
A escolha profissional é um fenômeno complexo, que virtualmente envolve todos os sujeitos nas sociedades contemporâneas, dada a centralidade do trabalho na constituição da subjetividade e identidade. O ensaio objetiva apresentar a escolha, no contexto nacional, como fenômeno cujo significado é social e culturalmente construído, balizado por fatores que remetem à própria constituição da sociedade brasileira. Para tanto, oferece-se primeiramente algumas considerações teóricas sobre a noção de profissão. Adicionalmente, busca-se analisar o fenômeno profissional no Brasil e sua articulação com o sistema de ensino superior e com a própria estrutura social no país, marcada pela desigualdade. Em suma, especula-se que a escolha profissional esteja condicionada a fatores macrossociais, inserida num processo de reprodução social, em que portadores de capital econômico e cultural se apresentam em condição de mobilizar recursos para a tomada de decisão, ao passo que os menos abastados têm essa possibilidade cerceada.
\end{abstract}

Palavras-chave: Escolha profissional; Profissões; Reprodução social; Educação superior.

\section{HIGHER EDUCATION AND PROFESSIONAL CHOICE IN BRAZIL}

\begin{abstract}
Career choice is a complex phenomenon that involves virtually every individual in contemporary societies, given the centrality of work in the constitution of subjectivity and identity. This essay aims to present the process of career choice, in the Brazilian context, as a socially and culturally constituted phenomenon. Theoretical remarks regarding the notion of profession are presented. The phenomenon of professionalism in Brazil and its relation to the higher education system and the Brazilian social structure itself, both marked by inequality, is analyzed. It is pointed out that career choice is affected by social reproduction, for people with economic and cultural capital are in a more favorable position to
\end{abstract}


mobilize resources for decision-making, while people from unfavorable socioeconomic backgrounds lack the right means to accomplish a self-assured choice.

Keywords: Career choice; Professions; Social reproduction; Education, Higher.

\section{INTRODUÇÃO}

A escolha profissional é um fenômeno complexo, que virtualmente envolve todos os sujeitos nas sociedades contemporâneas, dada a centralidade do trabalho na constituição da subjetividade e identidade.

Desse modo, tendo se desenvolvido como a área do conhecimento que aborda o comportamento e subjetividade humanos, em sua interação com o meio, a Psicologia apresenta uma rica produção acumulada a respeito do tema da escolha profissional. ${ }^{(1-7)} \mathrm{Em}$ função da intensa atividade de pesquisa, surgem diversas abordagens teóricas ao fenômeno, que, por sua vez, produzem uma robusta literatura e inúmeros modos de intervenção no processo de escolha, muitas das quais acabam por depositar demasiada ênfase nas características individuais, traduzidas em conceitos como vocação, aptidão, interesse e personalidade, que, ao fim e ao cabo, acabam realçando o papel do sujeito na escolha. ${ }^{(8)}$

A partir de tais referenciais teóricos, no entanto, é possível identificar um perigoso movimento de intensa valorização de traços pessoais associada a um enfraquecimento de uma análise ampliada, passível da identificação de diversos elementos sociais que incidem com força sobre a escolha. Nesse sentido, o objetivo do presente ensaio é problematizar a noção de escolha profissional, lançando um outro olhar à questão, partindo do pressuposto de que a opção por uma carreira profissional apresenta diversas dimensões de análise, sendo muitos os elementos que interferem em tal processo.

Em última instância, busca-se apresentar a escolha, no contexto nacional, como fenômeno cujo significado é social e culturalmente construído, balizado por fatores que remetem à própria constituição da sociedade brasileira. Para tanto, oferece-se primeiramente algumas considerações teóricas sobre a noção de profissão. Adicionalmente, é analisado o fenômeno profissional no Brasil e sua articulação com o sistema de ensino superior e com a própria estrutura social no país, marcada pela desigualdade perpetrada por esse mesmo fenômeno.

\section{PROFISSÃO: A BUSCA POR UMA DEFINIÇÃO}

A noção de profissão é, com efeito, tão corriqueira que uma tentativa de delineá-la conceitualmente aparenta uma tarefa desprovida de propósito, cujo resultado não passaria de um ato tautológico. Contudo, palavra polissêmica que oferece inclusive sentidos opostos entre si, ela é um construto social irredutivelmente complexo resultado de uma longa evolução semântica.

Hoje utilizada para referir ao ofício de um indivíduo, a palavra profissão tem origem no termo latino professione, designando "a ação de declarar, de ensinar uma profissão, de exercer um ofício".(9) Com o passar do tempo, o sentido da palavra ganhou um sentido especializado, não se referindo mais ao ato de ensino, mas ao ofício em si. Inicialmente, usada para designar a atividade docente de um indivíduo pertencente a qualquer das três faculdades superiores - Medicina, Direito e Teologia -, a palavra profissão passou a referir-se também ao exercício ocupacional. ${ }^{(10)}$ 
Na língua inglesa, a partir da qual o conceito moderno de profissão se desenvolve, o termo profession, passou a ser identificado para designar quaisquer ocupações desenvolvidas a partir da qual as pessoas ganhavam a vida e obtinham seu sustento, sendo apenas no século XIX que o termo vai referir-se a um número restrito de ocupações desenvolvidas por uma renovada e reorganizada classe média - condição que vai moldar a compreensão contemporânea do termo. Tal virada semântica aconteceu no mesmo momento em que, no âmbito do ensino superior, a educação liberal começa a perder relevo para o treinamento especializado em determinadas profissões na Inglaterra e Estados Unidos. ${ }^{(10)}$

Em países da Europa Continental, especialmente Alemanha e França, há também transformação análoga na missão da educação superior. ${ }^{(11)}$ Embora tendo desenvolvido distintos sistemas de ensino superior ao longo do século XIX, a tradição francesa sendo mais pragmática e técnica, ao passo que a germânica se voltou ao preparo científico, ao fim, ambas convergiam no objetivo de formação profissional de indivíduos com papéis técnicos específicos no sistema econômico capitalista, já plenamente desenvolvido na época. ${ }^{(12)}$

Nesse sentido, embora as instituições de ensino superior tenham sido desde a Idade Média o sítio de formação profissional, é na transição entre os séculos XIX e XX que a relação se intensifica. Com a expertise administrativa e o know-how científico cada vez mais requisitados no mundo do trabalho, a constituição social das profissões veio repousar na performance do conhecimento de nível superior, espaço de produção e reprodução das habilidades acima destacadas. ${ }^{(11)}$

Nos países de tradição anglo-saxã, caracterizados por contextos nacionais envoltos por uma economia de mercado e um Estado não muito atuante, essas profissões começam a se organizar de modo a obter controle de mercado. ${ }^{(10)} \mathrm{Em}$ países da Europa Continental, o processo de formação das profissões difere ligeiramente, na medida em que os Estados, nesses países, eram mais presen- tes na economia e na regulação da vida social. ${ }^{(10,13)}$ De todo modo, em ambos os contextos, buscando lugar seguro e privilegiado no mercado de trabaIho, essas ocupações buscaram, por meio da autorização estatal, validar o monopólio de serviços num processo de fechamento social. ${ }^{(13-17)}$

Assim, começou a tornar-se clara a noção de que certo tipo de conhecimento formal diferenciava profissionais de outros grupos ocupacionais. Tal conhecimento era obtido a partir de uma educação especializada, que se tornou então credencial básica para profissionais, fundamentando sua expertise e estabelecendo a distinção das profissões como uma classe ou categoria de ocupações especial. O sentido mais estrito de profissão que se conformava resgata a origem do termo, referente às learned professions, denotando a partir do século XIX uma ocupação aprendida por meio de um treino de nível superior, tanto em universidades quanto instituições especializadas. ${ }^{(10)}$

A partir de então, delineia-se uma acepção positiva, que ressaltava a forte consciência ética e a inclinação beneficente dos novos grupos profissionais para com a sociedade. Tal acepção se torna uma das características essenciais à definição do que seria uma profissão, tema que passou a ser encarado com preocupação por um número cada vez mais crescente de autores, em inícios do século XX.(10)

Nessa época, começam a surgir trabalhos preocupados com a natureza do exercício profissional, status das profissões e critérios definidores desses novos grupos. Abraham Flexner foi um dos primeiros a trabalhar o conceito de profissão, definindo-o a partir de seis critérios: i) desenvolvimento de operações intelectuais de alta responsabilidade; ii) matéria-prima derivada da ciência e aprendizagem formal; iii) trabalho baseado em fins práticos e definidos; iv) comunicabilidade técnica, geralmente instrumentalizado pelo uso do jargão ocupacional; v) auto-organização em classes profissionais; vi) direção altruística em sua atividade laboral. ${ }^{(18)}$

Mais tarde, autores como Carr-Saunders e Wilson, ${ }^{(19)}$ Halliday ${ }^{(20)}$ e Greenwood, ${ }^{(21)}$ vão reafirmar 
o interesse no debate sobre as profissões, cujo enfoque ao fenômeno de profissionalização de determinados grupos ocupacionais era no estabelecimento de critérios que marcassem essa distinção, apontando, em alguns casos, condições normativas para o enquadramento de alguns grupos no seleto grupo das profissões. $\mathrm{Na}$ medida em que seu principal foco era elencar uma lista de atributos necessários a uma determinada profissão, tais investidas ficaram conhecidas como abordagens taxonômicas. ${ }^{(22-23)}$

Geralmente, estavam entre as condições definidoras de um grupo profissional o conhecimento de base intelectual adquirido por meio da instrução superior, a existência de um código de ética, a direção altruística de trabalho e a existência de credenciais educacionais, fechamento corporativo e cultura própria. A partir desses autores, começa a delinear-se a sociologia das profissões, como campo especializado do conhecimento sociológico.

Especialmente a partir da década de 1970, novos estudos vão propor um novo direcionamento ao campo. Em oposição às abordagens taxonômicas, frequentemente acusadas de acríticas e a-históricas, por oferecer uma perspectiva meramente descritiva de análise, surgem novas orientações para o estudo do fenômeno profissional, denominadas perspectivas neo-weberianas, cuja centralidade de análise está na interpretação da profissionalização como um processo sociopolítico envolvendo interesses de mercado e jogos de poder, em nível macro. Assim, reconhecia-se que apenas elencar um conjunto de características não era suficiente para a caracterização profissional do fenômeno. ${ }^{(22)}$

A abordagem neo-weberiana centra-se, portanto, no princípio de que se vive um mundo dinâmico e competitivo de interesses, no qual os grupos ocupacionais obtêm e/ou mantêm reconhecimento profissional baseado na criação de fronteiras legais que marcam sua posição específica. Nesse sentido, a profissionalização, é marcada por uma forma particular de regulamentação, que está tipicamente vinculada a melhores condições de vida para os membros de tais grupos profissionais, minimamente em termos de renda, status e poder. ${ }^{(22)}$
Assim, a raiz da definição do conceito de profissão reside na ideia de um fechamento ocupacional sancionado pelo Estado, autorregulado em entidades profissionais, com suas regras próprias de inscrição, entre as quais estão a prévia obtenção de credenciais educacionais.

A partir de tal perspectiva, faz-se necessário o entendimento de profissão não como conceito único, geral, aplicável a distintas sociedades e em momentos históricos apartados, mas como um construto histórico, vinculado a determinado espaço e época. Isto é, não um conceito rígido e universal, mas aberto e em constante construção, com inumeráveis nuances regionais.

No caso brasileiro, tratar de profissão requer identificar a própria formação da sociedade brasileira, visto que uma característica marcante do fenômeno profissional no país é o fato de que a obtenção dos direitos sociais está historicamente ligada à identidade profissional. Tal afirmação é crucial para entender a estrutura social brasileira, na medida em que "os grupos profissionais, no processo da construção da sua identidade e do seu lugar social, são elementos essenciais na configuração do padrão de relações sociais dominante no Brasil". ${ }^{(24)}$

Por essa razão, na seção a seguir, destaca-se a maneira como o fenômeno profissional se desenvolve no contexto brasileiro, apontando suas peculiaridades, bem como a maneira como se entrelaça à formação da sociedade.

\section{EDUCAÇÃO SUPERIOR E O FENÔMENO PROFISSIONAL NO BRASIL: MANUTENÇÃO DAS DESIGUALDADES SOCIAIS}

Estritamente ligados ao empreendimento de colonização, os primeiros propósitos educacionais no período colonial couberam aos jesuítas, cujos colégios serviram como instrumento de formação da elite colonial. ${ }^{(25)}$ De caráter humanístico e intelectual, em sua gênese, a educação brasileira foi mar- 
cada pela falta de organicidade. Em meio à ausência de normatividade e regulamentação, o ensino foi fomentado para a manutenção dos privilégios dos segmentos dominantes.

Havia, nos colégios dos jesuítas, notadamente o da Bahia, cursos de Filosofia e Teologia, que desenvolviam uma atividade educacional posta a serviço da exploração da colônia, bem como aos propósitos da administração local. O sólido aparelho repressor estava estruturado numa administração fiscal e jurídica, secundada por um aparelho ideológico coincidente com a Igreja, cuja burocracia estava integrada à burocracia estatal. ${ }^{(26)}$

Tal aparelho objetivava difundir as ideologias legitimadoras da exploração colonial, voltada para o esforço dos integrantes do aparelho repressivo, para a aceitação da dominação metropolitana e para a ressocialização dos indígenas, de modo que os integrasse à economia da colônia como força do trabalho servil. Os colégios dos jesuítas então apresentavam uma função tripla: a formação de sacerdotes; formação de recursos humanos para o aparelho repressor colonial (oficiais de justiça, da fazenda e da administração); e ilustração das elites, com ensino humanístico e inculcação de preceitos religiosos-ideológicos de modo a sustentar o aparelho estatal, suas normas sociais, econômicas, políticas e familiares. ${ }^{(26)}$

A expulsão dos jesuítas, no bojo das Reformas Pombalinas, provocou a desarticulação do sistema educacional da colônia. A combalida educação superior brasileira só voltaria a se estruturar após a chegada da família real, com a criação de cursos superiores, faculdades, escolas e academias, os quais passariam por futuras reformas e teriam regulamentação mais detalhada, no período do Império, razão pela qual o ano de 1808 é comumente apontado como o início da educação superior no país. ${ }^{(26)}$ Essa visão, no entanto, revela-se imprecisa, dado o desenvolvimento precedente dos cursos superiores nos colégios dos jesuítas. Esse equívoco histórico parece apontar para uma característica frequentemente denunciada, a saber, a marcada orientação profissionalista - a um ponto tal que mesmo a historiografia educacional tem adotado a criação de instituições voltadas para o ensino de profissões como ponto de gênese das experiências em educação superior.

Poucos dias após aportar na cidade de Salvador, em 1808, D. João VI cria a Escola de Cirurgia, depois batizada Faculdade de Medicina da Bahia, hoje integrando a Universidade Federal da Bahia. No mesmo ano, é instalada a Escola Anatômica, Cirúrgica e Médica do Rio de Janeiro. Ambas são elevadas à categoria de faculdade em 1832. Em 1827, já haviam sido criados os cursos de Ciências Jurídicas e Sociais em São Paulo e Olinda, tornando-se faculdades em 1854. Completando o grupo das chamadas profissões imperiais, ${ }^{(27)}$ as Engenharias desenvolvem-se ao longo do século XIX, com a implantação de cursos e Escolas Militares, $\mathrm{Na}$ vais e de Minas no Rio de Janeiro e Ouro Preto. Do modo como foram organizados esses primeiros cursos superiores, duas características são marcantes: a organização autônoma não-universitária e a orientação profissionalista.

Tais características, reflexo da forte inspiração cultural francesa, delineou a organização do sistema de educação superior no país, que hipervalorizou a função de treinamento profissional. As faculdades e escolas que foram criadas a partir do século XIX, constituíram-se exclusivamente como nicho de formação das camadas superiores da sociedade, com o intuito de prepará-las para as atividades político-burocráticas e para o exercício das profissões liberais. ${ }^{(26-29)}$

Nesse particular, suscita-se a análise da educação superior brasileira em sua missão de formação profissional, a partir da contribuição da sociologia reflexiva de Pierre Bourdieu, com a noção de reprodução social, que se refere às diversas estratégias empreendidas por determinados grupos para a manutenção da ordem social. (30) Sendo as sociedades capitalistas pautadas numa relação entre dominantes e dominados, estes últimos encontram-se submetidos a um processo de naturalização da ordem social que a faz reproduzir-se no reconhecimento e desconhecimento da arbitrariedade que a institui.(31) Nesse processo, 
em que opera, em grande medida, o habitus, isto é, esquemas inconscientes de percepção, a reprodução social se efetua por meio de relações entre poder material e simbólico. ${ }^{\left({ }^{30}\right)}$ À reprodução social precede, portanto, a reprodução cultural, ${ }^{(32)}$ o que equivale a dizer que a transmissão de certos valores e hábitos culturais age diretamente na perpetuação da estrutura social, com desigualdades, na medida em que expressam a cultura das camadas dominantes.

Nesse caso, entre as estratégias empreendidas de reprodução cultural e social, situam-se as estratégias educativas, as quais objetivam, pela escolarização, produzir agentes sociais aptos a receber a herança de um determinado grupo social, tanto o legado econômico quanto o cultural, além das estratégias ideológicas de legitimação dos privilégios. ${ }^{(30)} \mathrm{O}$ sistema educacional, portanto, torna-se instrumento de reprodução das desigualdades, isto é, instrumento de reprodução das próprias estruturas sociais.

Dessa maneira, a partir da noção de capital cultural, (33) entendido tanto como incorporação de hábitos assimilados de maneira inconsciente como sua objetivação em suportes materiais, é possível entender como o diploma - objetivação do capital cultural - torna-se elemento de alto valor simbólico. Por sua capacidade de reconversão em capital econômico, ${ }^{(34)}$ garante ao seu portador os meios financeiros para convertê-los em capital cultural, estabelecendo um ciclo de manutenção das elites em sua posição de poder. Logo, perseverava o status quo, através das estratégias de reprodução social.

Dessa maneira, o modelo educacional profissionalista encontrou sólido terreno na homogeneidade político-ideológica dos grupos dominantes, produzindo um ciclo em que a formação superior conduzia ao diploma, que por sua vez, habilitava ao exercício das profissões liberais ou entrada nas carreiras do Estado, dotando esses indivíduos de um capital econômico, simbólico e social que thes permitia sustentar uma posição de destaque na hierarquia social.

A nova aristocracia que surgia, "de toga e beca", (35) substituía o patriarcado rural que começava a en- trar em decadência, resultado de transformações políticas, econômicas e sociais que o país enfrentou na passagem do período colonial ao Império, e assentava-se nesse mecanismo de reprodução. A nação, então, passa a ser erigida pelo trabalho político dessa nova casta e se edifica numa nova estrutura social baseada no poder e prestígio adquiridos pelos bacharéis. ${ }^{(35)}$ Sobretudo no caso do bacharel em direito, o diploma não habilitava somente ao exercício da carreira profissional, mas estava associado ao ingresso na burocracia estatal, no funcionalismo público ou na carreira política, bem como no jornalismo, na literatura, no magistério, em suma, no exercício do poder. Portar o diploma de bacharel, era alcançar uma casta que se legitimava por meio da posse desse título, como forma de distinção e estratégia de legitimação de dominação e de poder.

Desse modo, a formação dos grupos profissionais no Brasil representa uma terceira via, às duas outras previamente identificadas, ${ }^{(10)}$ ora com elementos da tradição anglo-saxã, ora com elementos que se aproximam da constituição europeia-continental, e com um tempero essencialmente nacional. "Regulação aqui, laissez-faire acolá". ${ }^{(27)}$ Tais grupos que passaram a ganhar notoriedade a partir de meados do século XIX foram centrais à própria formação do Estado e da sociedade brasileira, marcados pelo fenômeno do bacharelismo. (35)

A tardia educação superior brasileira, restrita em seus primórdios a escolas e faculdades profissionais, configurou-se como um nicho de formação das elites do país. Com efeito, por serem responsáveis pela formação profissional, as escolas, faculdades e instituições educacionais de nível superior contribuíram, no Brasil, para a reprodução da má distribuição de recursos e oportunidades entre grupos distintos.

Pondo em números tal assertiva, em 1908, de uma população girando em torno dos 20 milhões de habitantes, registrava-se apenas 6.735 estudantes de ensino superior, totalizando um efetivo inferior a $1 \%$ da população nacional. ${ }^{(36)}$ Juntas, as características elitistas e a inclinação profissionalista vão delinear 
a formação da sociedade brasileira, separando uma minúscula elite profissional de um enorme contingente populacional alheio a qualquer espécie de escolarização, primária ou superior.

Nesse quadro, a conquista da cidadania no Brasil ocorreu associada a um sistema de estratificação ocupacional. $\mathrm{Na}$ prática, os direitos de cidadão vinculam-se a ocupações reconhecidas e definidas em lei, situação qualificada como cidadania regulada, na qual a extensão da cidadania se fez a partir da regulamentação de novas profissões e/ou ocupações. Desse modo, a cidadania se faz embutida na profissão e os direitos do cidadão tornam-se restritos ao lugar que ocupa no processo produtivo, tal como reconhecido por lei. "Tornam-se pré-cidadãos, assim, todos aqueles cuja ocupação a lei desconhece". (37)

Nesse contexto, tendo o mercado como característica comum à qual são submetidos todos os grupos sociais, as profissões caracterizam-se por conseguir estabelecer regras diferenciadas para sua presença nessa instância da vida social.(24) Daí que, no Brasil, para além do fato de estar assentado em credenciais educacionais, o exercício profissional configurou-se por meio de uma legislação diferenciada que o colocava fora da estrutura sindical típica de outras ocupações, baseando-se em conselhos federais e regionais cujo objetivo de fiscalização completa a ideia de regulamentação profissional na legislação brasileira, que se delineou nos anos imediatos a 1930. Como resultado, tal regulamentação "moldou para as profissões de nível superior o estatuto de uma verdadeira aristocracia ocupacional com seus monopólios, privilégios e mecanismos de representação de interesses corporativos". (27)

A partir da década de 1930, o desenvolvimento nacional rumo à industrialização acentua-se, exigindo do Estado uma maior atenção à questão educacional e de qualificação da mão de obra. Como consequência, são cada vez maiores as taxas de escolarização da população e o número de matrículas no ensino superior, num processo iniciado ainda na velha república, quando trabalhado- res urbanos que começavam a povoar as cidades e imigrantes percebem a possibilidade de adentrar a estrutura burocrática do Estado, se portadores do diploma de nível superior.

O período da República Populista (1945-1964) revelou-se crucial para a educação superior nacional, com um crescimento responsável por um salto no número de universidades: de 7 para 39, e uma taxa de crescimento anual do número de matrículas de aproximadamente $12,5 \%$, contra a taxa de 2,4\% no período entre 1932-1945. Ao final da era populista, o país contabilizava 142.386 estudantes nas universidades e escolas superiores - um crescimento de $236,7 \%$. ${ }^{(38)}$

Conforme o Brasil diversificava seu parque industrial e ampliava serviços, a demanda por educação superior crescia. Contudo, a oferta de vagas não acompanhou essa demanda. Durante as décadas de 1960 e 1970 houve um imenso contingente de jovens que não logravam ingresso nas instituições de ensino superior, os chamados excedentes. (39) Essa demanda representava a tomada de consciência, por parte da classe média, da educação como instrumento de ascensão social.(40) Não importava a qualidade do ensino, mas o seu produto: o diploma. Nesse período, o retraimento do ensino público no atendimento dessa demanda ocasionou a escalada do processo de privatização, havendo incremento considerável da oferta de vagas nas instituições particulares de ensino superior. Observou-se que os índices de matrícula por dependência administrativa, no período 1960-1972, apresentaram crescimento global de $540,8 \%$ nas universidades, havendo um incremento de $484,7 \%$ nas instituições públicas e $718,4 \%$ nas privadas. Os estabelecimentos isolados, particulares em sua maioria, alcançaram um índice de $1.083,4 \%$ no mesmo período.(39) Entre 1965 e 1980, as matrículas do setor privado saltaram de 142 mil para 885 mil alunos. De minoria, o setor passou a represen$\operatorname{tar} 64 \%$ das matrículas. ${ }^{(41)}$

Se por um lado, a reforma universitária de 1968 modernizou boa parte das universidades públicas, sobretudo as federais, e mesmo até algumas con- 
fessionais privadas, criando condições de maior articulação entre ensino e pesquisa e promovendo uma reestruturação organizacional, por outro o setor privado observou uma escalada gigantesca, num claro processo de privatização da educação superior. ${ }^{(41-45)}$

Finalmente, após décadas de escalada, a rede privada chega à década de 1990 correspondendo a $62 \%$ das matrículas. ${ }^{(41)} \mathrm{A}$ década de 2000 , por sua vez, registra um movimento paradoxal. Por um lado, o setor público volta a crescer, em número de instituições e matrículas. As universidades federais se expandem. O tema da reforma universitária mais uma vez retorna à pauta política e as instituições se engajam na construção de uma nova proposta de educação superior, o que demonstra revitalização da rede pública, precarizada na década anterior. Por outro lado, a escalada do setor privado nunca foi tão acentuada, hoje correspondendo a $73 \%$ das matrículas. ${ }^{(46)}$

Já nos últimos anos, identifica-se uma manutenção na taxa de crescimento do número de matrículas, conjugada a uma ligeira diminuição do número de instituições, implicando o novo padrão comportamental do setor privado: a constituição e consolidação de holdings gigantescas - em números de estudantes, instituições e faturamento. ${ }^{(44)}$

Atualmente, embora a educação superior brasileira tenha passado por algumas transformações desde pelo menos a segunda metade do século $X X$, atingindo um cenário de expansão no número de matrículas e instituições, ocasionando a democratização do acesso, há ainda um atributo refratário a mudanças que promovam sua efetiva modernização.(37) Prevalece hoje o mesmo referencial profissionalista que constituiu a gênese das instituições de ensino superior no país, (47-51) visto que os dados do Censo da Educação Superior do ano de 2012 evidenciam o predomínio das matrículas em cursos de graduação referentes às profissões regulamentadas. Isto é, $74 \%$ do total de matrículas efetivadas são em cursos vinculados a apenas 41 campos profissionais. ${ }^{(52)}$
Herança da tradição luso-francesa, a educação superior brasileira demorou a se democratizar, permanecendo elitista e conservadora, habilitando os indivíduos para o exercício de profissões tradicionalmente liberais. Resultado da sua conformação tardia no início do século XIX, perpetua até os dias atuais mecanismos de reprodução e exclusão social, que se reproduzem sob nova configuração.

\begin{abstract}
Primeiro, uma minoria social e politicamente dominante, economicamente privilegiada, recebe benefícios fiscais de um Estado financiado pela maioria pobre. Essa minoria dominante tem recursos para pagar um ensino básico privado, em geral de melhor qualidade, subsidiado por forte renúncia tributária do imposto de renda à pessoa física. Em compensação, a maioria pobre que financia o Estado vai para escolas públicas de qualidade reduzida, incapaz de garantir seu acesso ao ensino superior público. Submetidos à educação superior privada de pior qualidade, os jovens pobres graduados têm menos empregabilidade, menor renda, mais desemprego, exclusão social, o que fecha esse primeiro ciclo de perversão social.
\end{abstract}

Segundo, esse ciclo é dominado pelo ciclo maior de reprodução de desigualdades sociais por meio da educação, porque a educação pública superior de melhor qualidade é gratuita para os ricos, pois o Estado nada lhes cobra. Pelo contrário, dá incentivos fiscais para que jovens não pobres tenham sua formação profissional custeada pelo Estado, e com isso acumulem mais capital político. E o ciclo se fecha, porque a reprodução da desigualdade social se completa quando esses jovens vão compor a nova geração da minoria dominante que, ao controlar empresas e governos, realimenta o processo. Isso ocorre porque historicamente sociedade e Estado no Brasil se acumpliciaram para tornar a educação não um elemento de inclusão social - o que seria um dever do Estado democrático, pois se trata de um direito de todos -, mas de reprodução das desigualdades sociais. ${ }^{(53)}$

Em suma, tendo em vista que, no contexto nacional, as profissões caracterizam-se como atividade ocupacional exercida com base no credenciamento educacional, conferindo privilégios econômicos e sociais, verifica-se que há pouca abertura a uma for- 
mação generalista, sendo o ensino superior buscado quase que exclusivamente em sua missão de formação profissional, que se configura como o cerne da reprodução das desigualdades sociais.

\section{A ESCOLHA PROFISSIONAL}

Embora seja costumeiramente reduzida à opção por um curso de graduação, a escolha profissional não ocorre pontualmente. É antes um processo que não se limita à entrada num curso de nível superior; pelo contrário, ela inicia mesmo antes da matrícula numa instituição e se prolonga durante o curso. A escolha profissional, como fenômeno social, envolve não apenas a consideração de características individuais ou das interações familiares dos sujeitos que escolhem, mas integra também o contexto local de interações do indivíduo com sua comunidade e bem como o âmbito macrossocial no qual estão inseridos.

Compreender, portanto, o processo de escolha significa adotar, antes de mais nada, um quadro teórico de referência amplo e integrado. Para tanto, apresenta-se um esboço de modelo teórico apoiado na antropologia da saúde de Gilles Bibeau. Desenvolvida, a princípio, para investigar o processo saúde-doença, tal proposta conforma "um marco conceitual que faz conexões entre as lacunas criadas pela tendência em fragmentar e decompor a realidade".(54)

São, em princípio, três dimensões que compõem o modelo proposto: a dimensão indivíduo-coletiva, a dimensão sociocultural e a dimensão político-econômica, sendo a interconexão entre as três o elemento central de apreciação, o que não exclui, no entanto, uma mirada minuciosa em cada uma das três dimensões. ${ }^{(54)}$ Parte-se, aqui, da premissa de que essa integração interpretativa que conforma uma perspectiva global, operacionalizada pela análise tripla, pode ser aplicada a outros fenômenos para além do processo doença-saúde, como a questão da escolha profissional.

Nesse sentido, a escolha seria considerada, na verdade, a culminação do processo de desenvolvimento da identidade profissional, podendo ou não levar à opção por uma trajetória de educação formal. Tal desenvolvimento ocorreria no tensionamento entre o micro e o macro, isto é, o indivíduo e o social, o biológico e o cultural, e obedeceria à premissa básica de que forças macrossociais, estruturas de poder, contexto histórico e valores culturais interfeririam no ordenamento psíquico da realidade e no comportamento humano, conforme apresentado na figura 1.

Figura 1 - Modelo de análise da escolha profissional

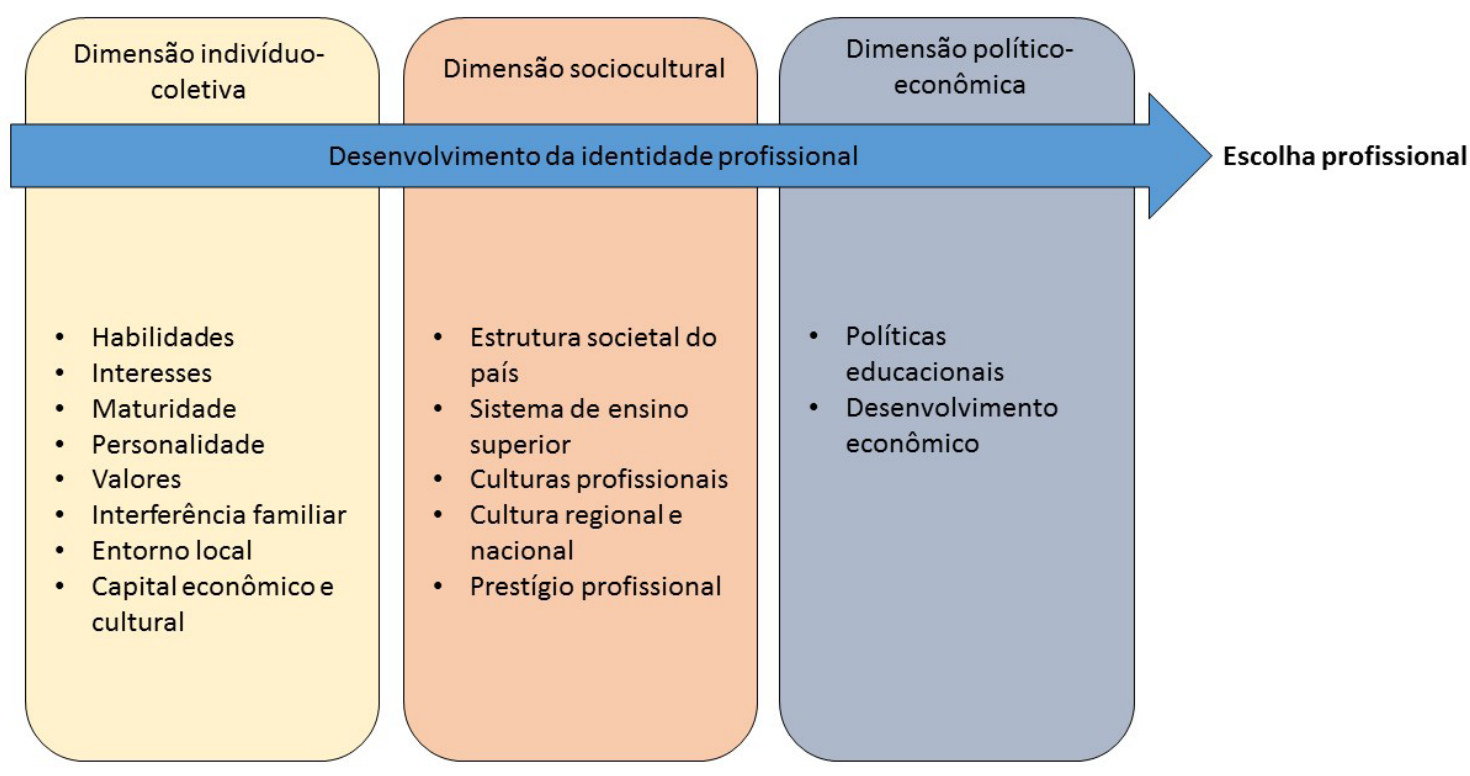


Na prática, a escolha ocorreria a partir da combinação de diversos fatores de ordem individual, como traços de personalidade, habilidades, interesses, maturidade e nível sociocultural, numa equação que envolve também as influências familiares, diretas ou indiretas. Todos esses fatores estariam ainda condicionados a características da estrutura societal e a dinâmica do sistema de ensino superior, bem como cultura e prestígio profissional; além, é claro, de aspectos mais abstratos, de ordem política e econômica, que envolvem, por exemplo, as políticas públicas educacionais.

Como já observado, há uma estreita relação entre as políticas educacionais para o ensino superior e a estrutura societal brasileira. Essa é uma condição fundamental para entender o processo de escolha profissional, na medida em que o diploma parece adquirir, na verdade, um fim em si mesmo, representando não mais que um passaporte para privilégios ou, minimamente, condições satisfatórias de vida num país marcado por grandes iniquidades sociais. Tal mecanismo de reprodução parece deliberadamente fomentado pelo Estado, na medida em que, desde pelo menos a década de 1970, com a progressiva e lenta democratização do acesso à educação superior, a orientação das políticas para o setor educacional tem valorizado a expansão por via das instituições privadas, voltadas quase que exclusivamente para o ensino, ou poder-se-ia dizer, para a venda do diploma.

Há, portanto, de modo geral, uma valorização da educação superior, e, em função do peculiar processo de desenvolvimento histórico brasileiro, uma tendência à valoração extremamente positiva de certas profissões, notadamente as ditas profissões imperiais, ${ }^{(27)}$ em detrimento das demais. Por um lado, alguns indivíduos, em função da posse de capital econômico e cultural, estão mais aptos que outros a gozarem mais facilmente da posição de escolha dessas profissões. Por outro lado, outros encontram-se limitados em sua escolha, por imposições de ordem socioeconômica, que cerceiam a capacidade de analisar o mundo do trabalho e suas facetas, dificultando o desenvolvimento e tomada de consciência da identidade profissional, fundamentais à realização de uma escolha segura.

Em suma, diante do exposto, a escolha nunca seria plena; ao contrário, estaria sempre condicionada a fatores de ordem extrínseca ao indivíduo, sendo as características pessoais talvez elementos de menor peso no processo de desenvolvimento da identidade profissional.

\section{CONSIDERAÇÕES}

Neste breve ensaio, buscou-se apresentar uma possibilidade de leitura teórica do processo de escolha profissional que englobasse a influência de forças sociais, afastando-se de uma concepção estritamente individualizante.

Através de uma revisão da composição do fenômeno profissional e do desenvolvimento do ensino superior no Brasil, problematizou-se a escolha, especulando seu condicionamento a fatores macrossociais, inserida num processo de reprodução social, em que portadores de capital econômico e cultural se apresentam em condição de mobilizar recursos para a tomada de decisão, ao passo que os menos abastados têm essa possibilidade cerceada.

Estando o caráter profissionalista da educação superior no cerne desse processo, convém indagar se, de fato, esse modelo de formação, que transforma jovens em candidatos a aprendizes profissionais antes de cidadãos, corresponde aos anseios por uma sociedade pautada em valores de equidade e justiça. Frente ao apresentado, tende-se a uma resposta negativa, na medida em que a valorização da formação profissional promove e reforça o condicionamento da cidadania ao exercício de carreiras profissionais, e contribui para a reprodução das desigualdades.

Nesse sentido, aponta-se a necessidade de superação desse modelo de educação superior anacrônico, substituindo-o por um paradigma assentado no desenvolvimento da cidadania e da autonomia pedagógica, que, por fim, forme cidadãos compe- 
tentes, socialmente compromissados, e aptos a atuar na sociedade contemporânea.

\section{REFERÊNCIAS}

1. Super DE. The psychology of careers: an introduction to vocational development. New York: Harper; 1957.

2. Holland JL. Making vocational choices: a theory of careers. Englewood Cliffs: Prentice-Hall; 1973.

3. Magalhães M, Straliotto M, Keller M, Gomes WB. Eu quero ajudar as pessoas: a escolha vocacional da psicologia. Psicol. cienc. prof. 2001;21(2):10-27.

4. Dias MSL; Soares DHP. A escolha profissional no direcionamento de carreira. Psicol. cienc. prof. 2O12;32(2):272-283.

5. Sparta M. O desenvolvimento da orientação profissional no Brasil. Rev. bras. orientac. prof. 2003;4(1-2):1-11.

6. Magalhães M. Matriz de habilidades e interesses. São Paulo: Casa do Psicólogo; 2011.

7. Ambiel RAM, Noronha, APP. Escala de autoeficácia para escolha profissional (EAE-EP): manual técnico. São Paulo: Casa do Psicólogo; $2 \mathrm{O} 12$.

8. Feijoo AMLC, Magnan VC. Análise da escolha profissional: uma proposta fenomenológicoexistencial. Psicol., Ciênc. Prof. 2002;32(2): 356-373.

9. Nascentes A. Dicionário etimológico da língua portuguesa. Rio de Janeiro: Francisco Alves; 1932.

10. Freidson E. Professional powers: A study of the institutionalization of formal knowledge, Chicago: Chicago University Press; 1988.

11. Jarausch K. Graduation and careers. In: Rüegg $W$, editor. A history of the university in Europe, v. 3. Cambridge: Cambridge University Press; 2004. p. 3-31.

12. Dobb M. A evolução do capitalismo. Rio de Janeiro: Zahar; 1977.

13. Harrits G. Professional closure beyond state authorization. Professions \& Professionalism. 2014;4(1):1-17.
14. Gonçalves CM. Profissões e mercados: notas de reflexão. Forum Sociológico. 2006;(15-16):15-32.

15. Wilson S. Professional closure: constructing the image of New Zealand nursing 1880-1940. Nurs. Prax. N. Z. 1998;13(1):12-22.

16. Chua W, Clegg S. Professional closure. Theory and Society. 1990;19(2):135-172.

17. Witz A. Patriarchy and professions: the gendered politics of occupational closure. Sociology. 1990;24(4):675-690.

18. Flexer A. Proceedings of the national conference of charities and correction; 1915 May 12-19; Chicago: Hildman; 1915.

19. Carr-Saunders AM, Wilson PA. The professions. Oxford: Oxford University Press; 1933.

2O. Halliday R. Problems involved in the classification of professional occupations. J. couns dev. 1949;27(8):530-534.

21. Greenwood E. Attributes of a profession. Soc. work. 1957;2(3):45-55.

22. Saks M. Defining a profession: the role of knowledge and expertise. Professions \& Professionalism. 2012;2(1):1-10.

23. Brante T. Professions as science-based ocupations. Professions \& Professionalism. 2011;1(1):1-17.

24. Barbosa MLO. As profissões no Brasil e sua sociologia. Dados. 2003;46(3):593-607.

25. Ribeiro M. História da educação brasileira: a organização escolar. $2 \mathrm{O}^{\mathrm{a}}$ ed. Campinas, SP: Autores Associados; 2007.

26. Cunha LA. A universidade temporã: o ensino superior da colônia à era Vargas. $3^{a}$ ed. São Paulo: EDUNESP; 2007.

27. Coelho EC. As profissões imperiais: medicina, engenharia e advocacia no Rio de Janeiro. 18221930. Rio de Janeiro: Record; 1999.

28. Oliveira MM. As origens da educação no Brasil: da hegemonia católica às primeiras tentativas de organização do ensino. Ensaio: aval. pol. públ. Educ, 2004;12(45):945-958.

29. Teixeira A. O ensino superior no Brasil: análise e interpretação de sua evolução até 1969. Rio de Janeiro: Ed. da FGV; 1969. 
30. Bourdieu P. Futuro de classe e causalidade do provável. In: Nogueira MA, Catani A, editors. Escritos de Educação. Petrópolis, RJ: Vozes; 1998.

31. Pinto L. Pierre Bourdieu e a teoria do mundo social. Rio de Janeiro: Ed. da FGV; 2000.

32. Bourdieu P. A economia das trocas simbólicas. São Paulo: Perspectiva; 1974.

33. Bourdieu P. Os três estados do capital cultural. In: Nogueira MA, Catani A, editors. Escritos de Educação. Petrópolis, RJ: Vozes; 1998.

34. Bourdieu P. Classificação, desclassificação e reclassificação. In: Nogueira MA, Catani A, editors. Escritos de Educação. Petrópolis, RJ: Vozes; 1998.

35. Freyre G. Sobrados e mucambos: decadência do patriarcado rural e desenvolvimento urbano. $5^{a}$ ed. Rio de Janeiro: José Olympio; 1977.

36. Nunes E. Desafio estratégico da política pública: o ensino superior brasileiro. Rev. Adm. Pública. 2007;41(n.esp):103-147.

37. Santos WG. Cidadania e justiça: a política social na ordem brasileira. $2^{\mathrm{a}}$ ed. Rio de Janeiro: Campus; 1987.

38. Cunha LA. A universidade crítica: o ensino superior na república populista. $2^{a}$ ed. São Paulo: EDUNESP; 2007.

39. Franco MAC. Acesso à universidade: uma questão política e um problema metodológico. Educação e Seleção. 1985;(12):9-26.

4O. Cunha LA. A expansão do ensino superior: causas e consequências. Debate \& Crítica. 1975;(5):27-58.

41. Martins CB. A reforma universitária de 1968 e a abertura para o ensino superior privado no Brasil. Educ. Soc. 2009;30(106):15-35.

42. Martins CB. Reconfiguring higher education in Brazil: the participation of private institutions. Análise Social. 2013;(208): 622-658.

43. Martins CB. O ensino superior brasileiro nos anos 90. São Paulo Perspec. 2000;14(1):41-60.
44. Gaspar R, Fernandes T. Mercantilização e oligopolização no ensino superior privado. Educação \& Realidade. 2014; 39(3):945-966.

45. Chaves VLJ. Expansão da privatização/ mercantilização do ensino superior brasileiro: a formação dos oligopólios. Educ. Soc. 2010;31(111):481-500

46. Instituto Nacional de Estudos e Pesquisas Educacionais Anísio Teixeira. Censo da Educação Superior 2012: resumo técnico. Brasília: INEP; 2014.

47. Almeida Filho N. Bacharelado interdisciplinar em saúde: revolução na educação superior no campo da saúde?. In: Teixeira CF, Coelho, MTAD, editors. Uma experiência inovadora no ensino superior: bacharelado interdisciplinar em saúde. Salvador: EDUFBA; 2014. p. 11-21.

48. Almeida Filho N. Universidade Nova: Nem Harvard nem Bolonha. In: Almeida Filho N, editor. Universidade Nova: Textos críticos e esperançosos. Brasília: Ed. UnB; Salvador: EDUFBA; 2007. p. 259-295.

49. Almeida Filho N. Universidade nova no Brasil. In: Santos BS, Almeida Filho N, editors. A universidade no século $X X I$ : para uma universidade nova. Coimbra: Almedina; 2009.

50. Nunes E, Carvalho MM. Ensino universitário, corporação e profissão: paradoxos e dilemas brasileiros. Sociologias. 2007;(17):190-216.

51. Fávero MLA. A universidade no Brasil: das origens à reforma universitária de 1968. Educar em Revista. 2006;(28):17-36.

52. Mayall GS, Albrecht JV. Relatório do censo da educação superior, ano 2012. Rio de Janeiro: Observatório Universitário; 2013.

53. Almeida Filho N. Contextos, impasses e desafios na formação de trabalhadores em saúde coletiva no brasil. Ciênc. saúde coletiva. 2013;18(6):1677-1682.

54. Bibeau G. A step towards thick thinking: from webs of significance to connections across dimensions. Med Anthropol Q. 1988;2(4):402 416. 